\title{
FINITE ELEMENT FATIGUE ANALYSIS OF UNSUPPORTED CRANE
}

\author{
Ryszard Buczkowski* \\ Bartłomiej Żyliński \\ West Pomeranian University of Technology Szczecin, Poland
}

*Corresponding author: rbuczkowski@ps.pl (R.Buczkowski)

\begin{abstract}
The presented strength and fatigue calculations refer to an unsupported deck crane and its three distinct parts: housing, jib and column. Static loads applied to the structure were due to the crane's own weight and a maximum working load, corresponding to a maximum lifting capacity at a maximum outreach of the crane. The numerical analysis was aimed at determining the thickness of the skin plating of the column and the number, shape and distribution of stiffeners in the column, housing and jib, ensuring that the crane yields correct strength and fatigue parameters. During the process of designing marine structures, the standard numerical analysis is, in many cases, limited to calculations in the basic strength range. Even when using numerical methods of analysis, complex strength and fatigue calculations are often not performed. The modern numerical analysis chain for marine structures should concentrate not only on strength analysis, but should take a further step, which encompasses fatigue analysis. The article presents a new outlook on design methods, which should be the entry point to the design of marine structures. Based on the acquired number of cycles offatigue life, it is possible to estimate, with a sufficient degree of accuracy, the practical service life of a structure. To solve the problem, the authors used the finite element analysis software ABAQUS supported by the fe-safe system.
\end{abstract}

Keywords: fatigue life analysis, strength analysis, fatigue factors, unsupported deck crane, FEM model

\section{INTRODUCTION}

Unsupported deck cranes are being installed more and more often on container ships all over the world. This is a response to ship owners' greater demands for larger container space on deck. More cargo room is gained by sacrificing whatever can be removed from the open deck, even by moving the superstructure further aft. For the same reason, naval architects tend to locate deck cranes on one side instead of on the ship's centre line. One such example is a new crane solution, the CBB 3800 from Liebherr, a powerful machine that can easily handle oversize cargo items.

The pursuit for greater ship efficiency leads to crane design restrictions, which may leave no space on the weather deck for the crane jib support used during the sea passage. In such a case, the installation of an unsupported deck crane is often the only compromise solution, despite the higher cost of such cranes and related operational problems. Besides this, unsupported cranes require more precise strength and fatigue calculations for crane housings and jibs, mounted on a column higher than ten metres.

Ships and other marine structures are, obviously, subjected to fatigue damage caused by dynamically acting waves and slowly changing loads, that occur during cargo handling operations. In a recent study [17], containing projected trends in offshore structures, the authors postulated the need for further investigation of fatigue damage prediction procedures. In turn, Hirdaris et al. [10] pointed out that to correctly assess and predict fatigue phenomena in offshore structures one has to have a design philosophy based on an analysis of model test results, field measurements and simulations using up-to-date numerical modelling systems. 
Today, fatigue analysis commonly makes use of two methodologies for solving problems of that type. One consists of an analysis utilising the S-N relation (stress - number of cycles to failure), the other is the fatigue crack growth (FCG) method.

Many research studies relating to fatigue analysis of various types of offshore structures have been based on these methods. Wirsching [21], for instance, presented results of fatigue tests on welded joints from steel offshore structures. The author's analysis took into account service life, wave spectra, water depth, platform dynamics and the location of the joint in the structure.

Fonte et al. [5], in turn, presented tests of welded joints and cracks on a crane pedestal of a container ship. The authors found that, although the crane column was subjected to fatigue processes, sudden loads during cargo operations and the phenomenon of crack corrosion found on the column surface may be due to normal crane operation as well as poor maintenance.

Deguchi et al. [4] examined the influence of the ultrasonic peening method on increases in the fatigue strength of welded joints in structural ship components. Taking into account changes in the distribution of stresses occurring over the entire service life of the ship, the authors proposed effective methods for using ultrasonic peening to improve fatigue strength.

Soares and Moan [20] proposed a special model of loading that should be considered when designing offshore structures. The model enables the assessment of fatigue damage in structural ship components.

Soares and Garbatov [19] presented an assessment of ship hull reliability, with respect to fatigue failure of the longitudinal stiffeners, as well as plating. Their formula allows modelling of the crack growth process.

Kvittem and Moan [13] undertook long term fatigue damage analysis for a semi-submersible wind turbine. They observed that it is essential for an analysis to adopt loading that will not cause high fatigue damage. Thus, we can obtain a reliable fatigue estimate for the adopted service life.

Lieurade [15] stated that wave loads, commonly acting on offshore structures over an assumed 20+ years of operation, caused about 1E8 cycles of stress variation and may be the main cause of potential fatigue cracking. The author referred to a number of offshore structures and the main factors affecting the formation of fatigue effects in these objects.

Hirdaris et al. [9] provided a wide overview of loads on maritime structures to support classification rule requirements and procedures. In their fatigue analysis, the authors took into consideration the loads acting on ships and offshore lifting structures.

Researchers are also interested in fatigue analysis of marine cranes. Marquez et al. [14] presented the causes of crane failures and similarities in failure circumstances. They examined a cylindrical luffing crane, designed to handle containers at a river port. Due to damaged bolts, the crane broke away from its base and collapsed into the water. The bolts fixed the non-rotating part of the crane to the base. After the damaged parts were recovered from the water, it was found that bolt damage was due to material fatigue and occurred prior to the catastrophic failure.

Using a FEM model and the NASTRAN system, Han et al. [7] presented an analysis of an offshore platform crane, aimed at examining deformations and stress distribution. Moreover, they made fatigue estimations to determine the life cycle of the welded boom structure. The analysis took into account the crane's own weight, maximum working load, wind pressure and wave action causing the ship's rolling motion.

Examining a quayside container crane, Wu et al. [22] applied a FEM model and MSC.Adams, MSC.Patran and MSC.Fatigue systems to present the analysis chain comprising the modelling of a structure, followed by strength and fatigue analyses.

Ozguc [23] presented non-linear FE results of ship-shaped offshore vessels, where the deck structure is exposed to buckling failure. The hybrid method (combination of the deformable finite elements and the concentrated mass method) was applied in [24] to design of some offshore steel structures. Samson and Kahsin [25] described numerical and experimental results of pre-tension forces in standing rigging of a mast.

The examples presented above, often do not encompass a complex numerical analysis. The processes of analysis should be conducted with the inclusion of industry codes, standards and classification society requirements.

We will attempt to present an effective chain of engineering analysis which contains numerical analysis using the Finite Element Method in the range of fatigue analysis.

\section{NUMERICAL MODEL OF THE UNSUPPORTED DECK CRANE}

This analysis deals with an unsupported deck crane with a lifting capacity of $400 \mathrm{kN}$ at a $32 \mathrm{~m}$ outreach, mounted on a $13.8 \mathrm{~m}$ column, an integral part of the ship's hull. The overall height of the crane, including the column, is $246 \mathrm{~m}$, while the $\mathrm{jib}$ is $34.4 \mathrm{~m}$ long. The adopted model naturally distinguishes three characteristic parts of the crane: column, housing and jib, as shown in Figure 1. The figure presents a discrete, finite element mesh model of the crane.

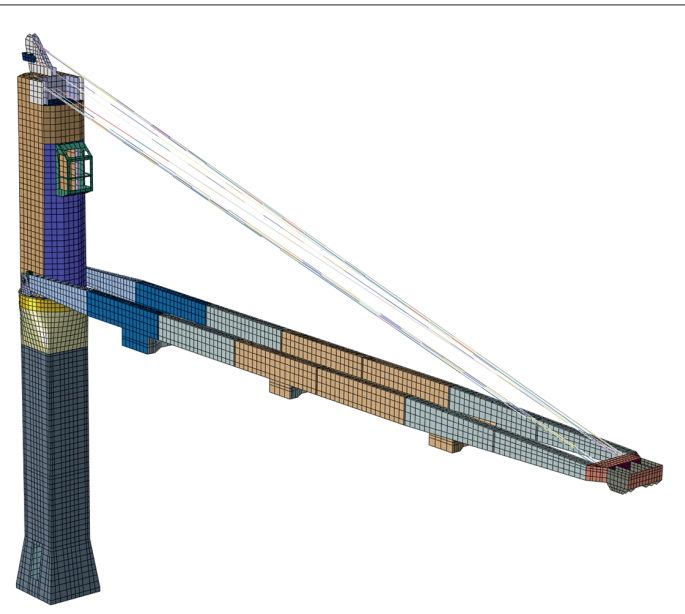

Fig. 1. A model of an unsupported deck crane mounted on a column 
The crane column functions as a base for mounting the housing at a required height so that the jib is located above the level of the top container tier. This allows maximisation of the use of space around the column by placing extra containers there. The column interior is used by crane operators to climb to the housing. The column interior comprises electric and hydraulic installations. The crane column is topped with a collar flange, to which the housing is bolted. The lower part of the housing is where the jib is attached by pins, held in a proper position by outreaching, changing ropes. Inside the housing are drive units for controlling the outreach and crane rotation and for cargo lowering and lifting. The numerical model, created with the finite element method, is composed of 17,352 elements and 64,879 nodes, which gives 365,478 degrees of freedom in total. To discretise the metal plates used for the shell and stiffeners of the housing, column and jib, we mainly used thin shell elements, denoted as S8R5, STRI65 (as in the ABAQUS system) [3].

The plate thicknesses ranged from 26 to $31 \mathrm{~mm}$ in the column, from 10 to $28 \mathrm{~mm}$ in the housing and from 10 to $25 \mathrm{~mm}$ in the jib (note the different colour markings in Figure 1). The stiffener distribution in the column and the jib is shown in Figure 2.

The method of modelling the crane's lifting ropes deserves special attention. The most often used ropes in rope structures are ordinary spiral or multi-strand plaited ropes, as well as prefabricated wire and rope cables [16]. Plaited ropes used in deck cranes are characterised by their high flexibility, allowing easy winding of the ropes on lead pulleys and high longitudinal deformability. The mechanical properties of ropes are substantially different from those of individual wires. The main difference is the value of Young's modulus E 16]. An arbitrary adoption of the modulus of elasticity in the numerical model may lead to significant differences between the calculated and actual states of displacements and stresses in the elements of the tie structures. When devices that may create hazardous situations are designed, the modulus of elasticity should be determined experimentally [16]. According to the Polish guidelines contained in relevant design standards [16], the values of the modulus of elasticity for plaited ropes range from $120 \mathrm{GPa}$ to $195 \mathrm{GPa}$. The value of the Young's modulus adopted for the numerical calculations was $\mathrm{E}=120 \mathrm{GPa}$. For rope modelling by the finite element method, the stiffness matrix of a tie element is obtained from the superposition of its elastic stiffness; it corresponds to the stiffness of a bar element and its geometrical stiffness, taking account of the longitudinal forces in a rope finite element $[1,12,16]$. For the calculations, 30 finite elements of the rope were adopted at each section from the jib end to the leading pulley block, mounted at the upper part of the housing.

Structural elements of cranes and other handling equipment are typically made of high strength, class 355 or normal strength, class 235 steel. In the DNV regulations, steels with similar strength properties (yield points) are classified as VL-36 and VL, respectively. The calculations assume that the crane is made of high strength steel (high strength, class 355). Steel grade S355J2G3 (EN10025-2) was adopted here, with

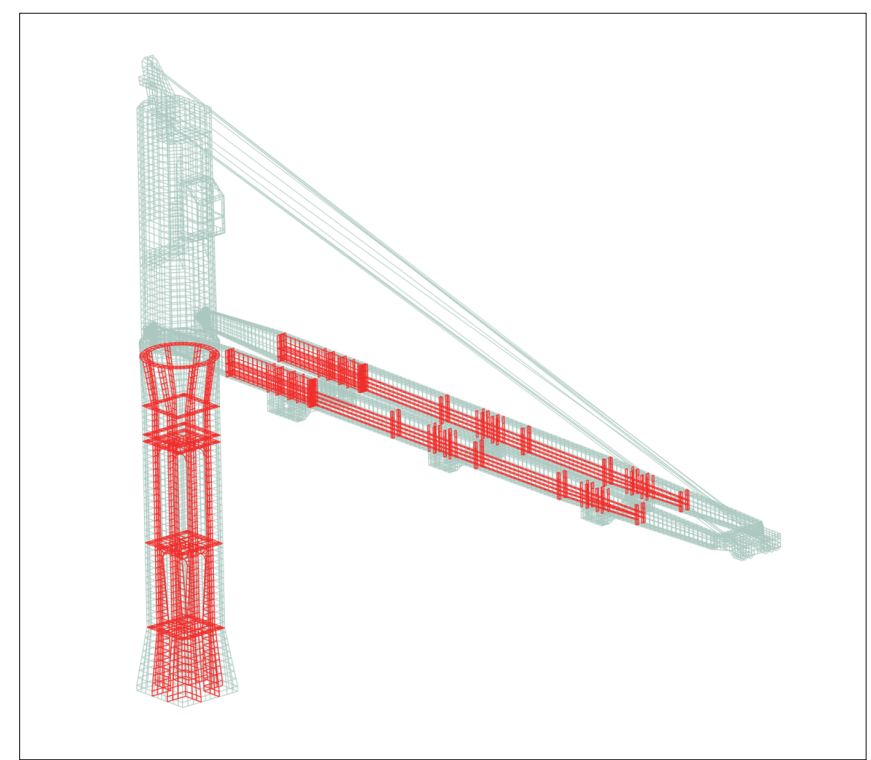

Fig. 2. Discretisation using finite elements of the column and jib internal transverse and longitudinal stiffeners

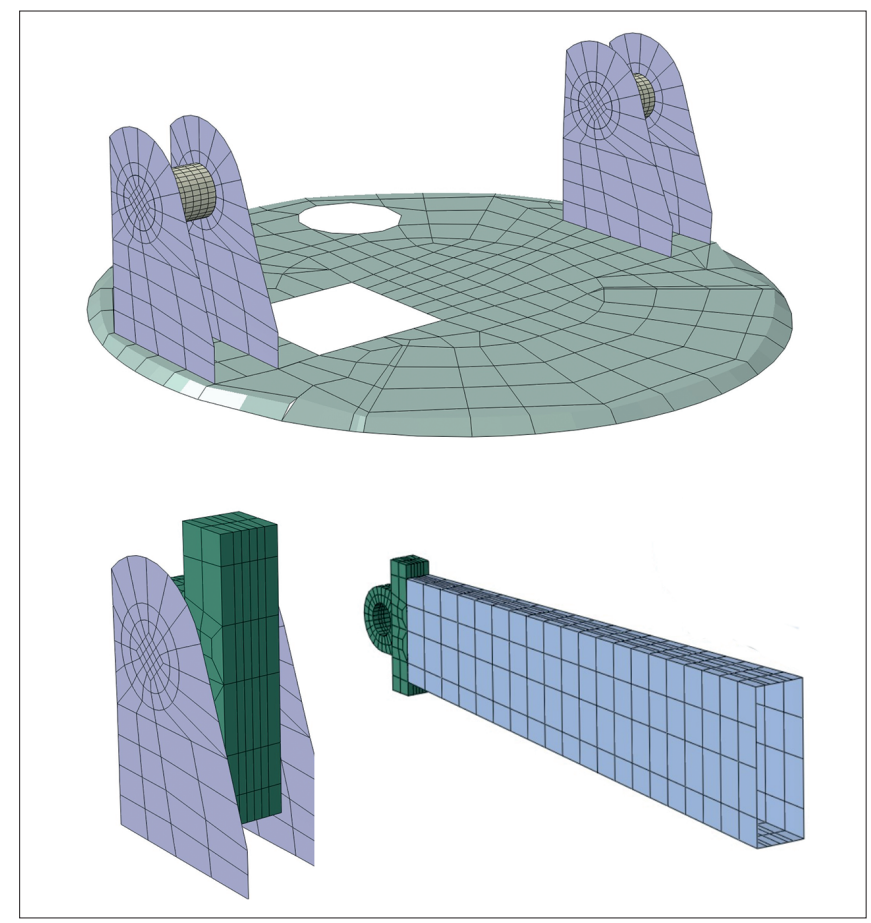

Fig. 3. A contact pin connection between the housing and the jib

a minimum yield strength of $355 \mathrm{MPa}$ (for a sheet thickness up to $16 \mathrm{~mm}$ ). For these steels, the S-N curves are published in the DNV regulations. In our calculations, it is steel marked as material B. For comparison, the possibility of using another steel material with the $\mathrm{S}-\mathrm{N}$ curve provided by the manufacturer (material A) was also tested.

\section{FATIGUE CALCULATIONS}

In engineering practice, it is generally estimated that more than half of the permanent damage to machinery is caused by fatigue changes occurring in a machine's component materials. In this context, it is essential to correctly use 
reliable engineering tools to assist the determination of fatigue strength. Fatigue analysis, utilising the finite element method, substantially reduces or, in some cases, eliminates the cost of re-designing or withdrawing faulty products. Besides, it is possible to curb the testing costs performed before a prototype is made. Customer satisfaction, due to solid and durable products, comes as an extra benefit.

Fatigue calculations for high cycle elements make use of a method based on assigning certain values of stress to the number of stress change cycles, this is well known to designers. Numerous sources $[6,26]$ state that the boundary between high cycle and low cycle fatigue life is 104 or 105 cycles. Besides the strict determination of a limit value, it is more important to accept the general principle that calculations of high cycle fatigue strength are used for work within an elastic range, while low cycle fatigue calculations refer to the elastic-plastic range.

In practical fatigue calculations, computer programs based on the finite element method (FEM) are currently used, which automates the entire calculation process. Classification institutions also offer software of this type, e.g. the SESAM system (DNV), which includes programs that enable the performance of strength calculations, in accordance with the requirements of the regulations of this institution.

The general-purpose FEM systems currently used, such as ANSYS or ABAQUS (together with the SIMULIA software package), are based on the results of static calculations, and they enable fatigue calculations to be performed. These calculations are performed by the appropriate module built into the postprocessor program (see the ANSYS Workbench - fatigue module). An example of such a program is 'fe-safe' which is delivered as part of the SIMULIA package (the manufacturer of 3DS-Dassault Systems) in cooperation with the ABAQUS program and other significant systems (NASTRAN, ANSYS).

The fe-safe program allows fatigue calculations to be performed with a wider scope and in a more advanced way than those required by the regulations and recommendations of classification institutions. The choice is between fatigue strength models based on Wohler stress relationships (known as S-N or "Stress-Life") and those based on deformation (known as "Strain-Life").

For the S-N type analyses, the program enables the definition of the transformation of the mean stress according to Godman, Gerber, Soderberg and others. For Strain-life analyses, the transforms given by Morrow, Smiths and others can be used. It is possible to define any fatigue load of characteristic load cycles: alternating, zero-pulsating, non-proportional or based on the readings of real signals (loads). The program includes a ready-made material database with assigned S-N curves. It is possible to define your own material library and the corresponding S-N curves and to define the correction of these curves due to the notch effect.

Fatigue analyses based on S-N ("Stress-Life") relationships are commonly used for high-cycle fatigue strength. As a rule, low-cycle fatigue analysis is based on deformation relationships ("Strain-Life"). As a result of the fatigue calculations, the durability (or portions of failure) is obtained according to the Palmgren-Miller hypothesis.
The capabilities of the fe-safe program (as well as the AnsysWorkbench and others) enable fatigue calculations based on $\mathrm{S}-\mathrm{N}$ curves, taking into account the appropriate correction factors contained in the regulations and recommendations of classification institutions, e.g. DNV. Results of the high-cycle $\mathrm{S}-\mathrm{N}$ fatigue analysis in one of the above-mentioned programs will be received in the same way as defined in the regulations of these institutions.

It should be noted that the fatigue calculation methods described above include the fatigue of the structure material. Fatigue calculations of welds are a separate issue and classification institutions have separate requirements in this regard.

\section{FATIGUE ANALYSIS ACCORDING TO THE REGULATIONS OF CLASSIFICATION INSTITUTIONS}

Classification institutions, such as Lloyd's Register or DNV (formerly known as Det Norske Veritas and Germanisher Lloyd, prior to a merger), issue separate classification and approval rules for on-board equipment, including lifting machinery and equipment. DNV has two separate standards for lifting appliances: one for offshore lifting appliances ("DNVGL-ST-0377 Standard for offshore and platform lifting appliances"), the other for conventional deck equipment, including the design of cranes mounted on merchant ships ("DNVGL-ST-0377 Standard for shipboard lifting appliances"). All of these regulations specify the number of load cycles in the expected service life and the fatigue strength.

Now, we briefly describe the requirements according to DNV. DNV for fatigue design is mainly based on the application of the S-N stress relationship, assuming linear cumulative damage (the Palmgren-Miner rule). The methodology is also widely described in the additional recommendation DNVGL-RP-0005 "RP-C203: Fatigue design of offshore steel structures”. For ship cranes, detailed fatigue strength requirements are specified in DNVGL-ST-0377 (Chapter 4.6). If they are in agreement with the classification institution, other recognised fatigue calculations may be used. Fatigue analysis is based on nominal S-N curves for plate structures. $\mathrm{S}-\mathrm{N}$ curves obtained from fatigue tests are given in the DNV regulations or recommended practice.

If the fatigue life estimation based on S-N data is insufficient for a component in which failure may lead to serious consequences, a more detailed study covering the greater part of the structure or the fracture mechanics analysis, should be performed.

In this article, we discussed the Miner's rule of cumulative damage; it is the simplest cumulative damage model. It states that if there are $K$ different stress levels and the average number of cycles to failure at the $i$-th stress, then the partial damage $D_{i}$ is determined as follows:

$$
D_{i}=\sum_{k=1}^{K} \frac{n_{k}}{N_{k}}
$$


where: $K$ is the total number of blocks of the stress range spectrum, $n_{k}$ is the number of stress cycles in block $k$ and $N_{k}$ denotes the number of stress cycles determined from the $\mathrm{S}-\mathrm{N}$ curve.

The above equation can be thought of as assessing the proportion of life consumed at each stress level and then adding the proportions for all the levels together. Often, an index for quantifying the damage is defined as the product of stress and the number of cycles operated under this stress, which is:

$$
W_{i}=n_{i} S_{i}
$$

Assuming that the critical damage is the same across all the stress levels, then:

$$
W_{\text {failure }}=N_{i} S_{i}
$$

Using Eq. (2) as the critical value of damage that will result in failure, Eq. (1) becomes

$$
D_{i}=\sum_{k=1}^{K} \frac{n_{k} S_{k}}{N_{k} S_{i}}=\frac{\sum_{k=1}^{K} n_{k} S_{k}}{W_{\text {failure }}}
$$

For example, if $W_{\text {failure }}=50$ for a component, it means that the component will fail after 10 cycles at a stress level of 5, or after 25 cycles, at a stress level of 2 .

It is assumed that the fatigue strength is achieved when the cumulative failure $D$ meets the condition:

$$
D=\sum D_{i} \leq 1
$$

When the damage fraction reaches, failure occurs.

\section{THE RESULTS OF NUMERICAL CALCULATIONS}

In the fe-safe program, the fatigue calculations were carried out in accordance with the requirements of the DNV classification, adopting the high-cycle fatigue analysis of the $\mathrm{S}-\mathrm{N}$ type. To perform the calculations requires the definition of the input parameters for the analysis. The most important of these are material data and the definition of a fatigue load. For comparison purposes, calculations were performed for two defined materials, i.e. steel with different S-N curves. For material A (steel, $\mathrm{Rm}=400 \mathrm{MPa}$ ), the S-N curve was taken from the fe-safe database (the selected values are shown in Table 2).

As a result of fem analysis, performed with ABAQUS, the displacement of the jib end under a maximum load of $400 \mathrm{kN}$ was $1,067 \mathrm{~mm}$ as depicted in Figure 4 .

For individual structural elements of the crane (jib, crane housing and column), the locations of the highest von Mises stresses were identified (Figure 4). These values are listed in Table 1.

Spot B in Figure 5 is located at a height of $13.9 \mathrm{~m}$ from the column base. The place of greatest effort in the column, marked as $\mathrm{C}$ in Figure 5, is found $11.5 \mathrm{~m}$ up from the column base, where the column changes its shape from a cuboid to a convex socket. Maximum reduced stresses in the jib are located $15.8 \mathrm{~m}$ from the jib end, denoted as A in Figure 5.

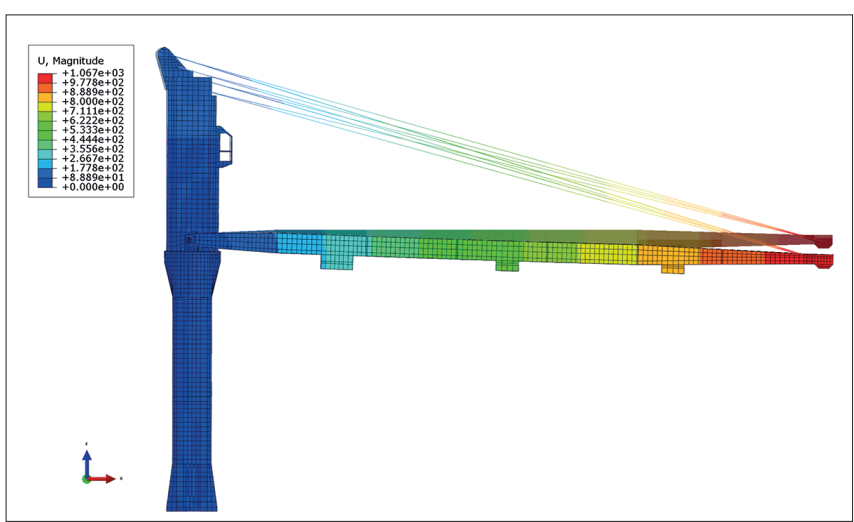

Fig. 4. Contour lines of the displacement under its own weight and working load of $400 \mathrm{kN}$ (compared to the undisplaced model)

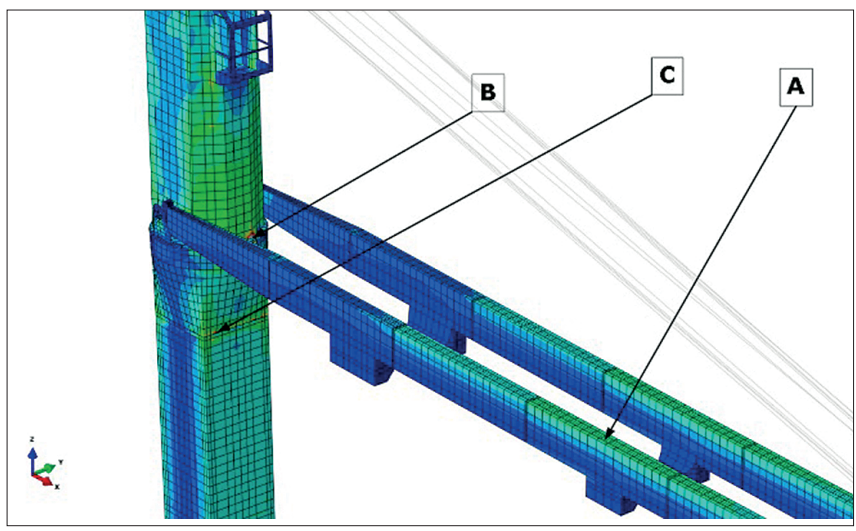

Fig. 5. Places of occurrence of the highest von Mises stresses $f$ or individual structural elements of the crane

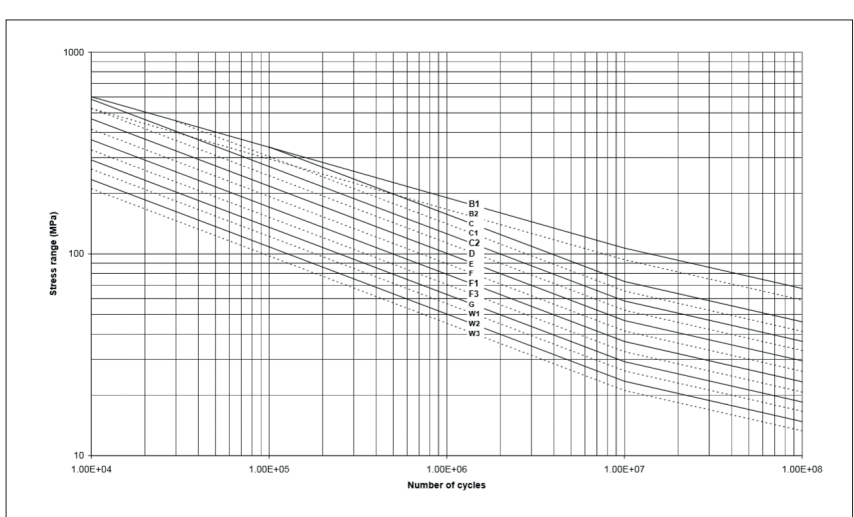

Fig. 6. S-N curves according to DNVGL ("RP C203 Fatigue design of offshore steel structures")

Tab. 1. The von Mises reduced stresses for structural elements of an individual crane

\begin{tabular}{|c|c|c|}
\hline Part of the crane & $\begin{array}{c}\text { Number of finite } \\
\text { elements }\end{array}$ & $\begin{array}{c}\text { Maximum von Mises } \\
\text { stress [MPa] }\end{array}$ \\
\hline Jib (A zone) & 102,214 & 105.555 \\
\hline Crane housing (B zone) & 300,714 & 368.251 \\
\hline Column (C zone) & 203,798 & 281.16 \\
\hline
\end{tabular}

Tab. 2 Material A (selected S-N values)

\begin{tabular}{|c|c|c|}
\hline Number of cycles & 10,000 & $1 \mathrm{E} 7$ \\
\hline Stresses & $363[\mathrm{MPa}]$ & $188.3[\mathrm{MPa}]$ \\
\hline
\end{tabular}


For material B, the S-N curve in the fe-safe program was defined on the basis of the DNV regulations and the curves presented therein, as in Figure 6.

Tab. 3. Results of fatigue calculations for selected points of the crane's structural elements. Material A

\begin{tabular}{|c|c|c|c|}
\hline $\begin{array}{c}\text { Part of the } \\
\text { crane }\end{array}$ & $\begin{array}{c}\text { Number of } \\
\text { finite elements }\end{array}$ & $\begin{array}{c}\text { Number of } \\
\text { cycles }\end{array}$ & Damage/cycle \\
\hline Jib (A zone) & 102,214 & $\begin{array}{c}\text { No fatigue } \\
\text { damage }\end{array}$ & $\begin{array}{c}\text { No fatigue } \\
\text { damage }\end{array}$ \\
\hline $\begin{array}{c}\text { Crane housing } \\
\text { (B zone) }\end{array}$ & 300,714 & 77,897 & $1.28 \mathrm{E}-05$ \\
\hline $\begin{array}{c}\text { Column } \\
\text { (C zone) }\end{array}$ & 203,798 & $2,286,472$ & $4.37 \mathrm{E}-07$ \\
\hline
\end{tabular}

Tab. 4. Material B (selected S-N values, curve B1)

\begin{tabular}{|c|c|c|}
\hline Number of cycles & 10,000 & $1 \mathrm{E} 7$ \\
\hline Stresses & $600[\mathrm{MPa}]$ & $106.97[\mathrm{MPa}]$ \\
\hline
\end{tabular}

For material B, the S-N curve in the fe-safe program was defined on the basis of the DNV regulations and the curves presented therein, as in Figure 6.

The zero-pulsating cycle was adopted as the fatigue load (Figure 7). Therefore, calculations should take mean stress corrections into account.

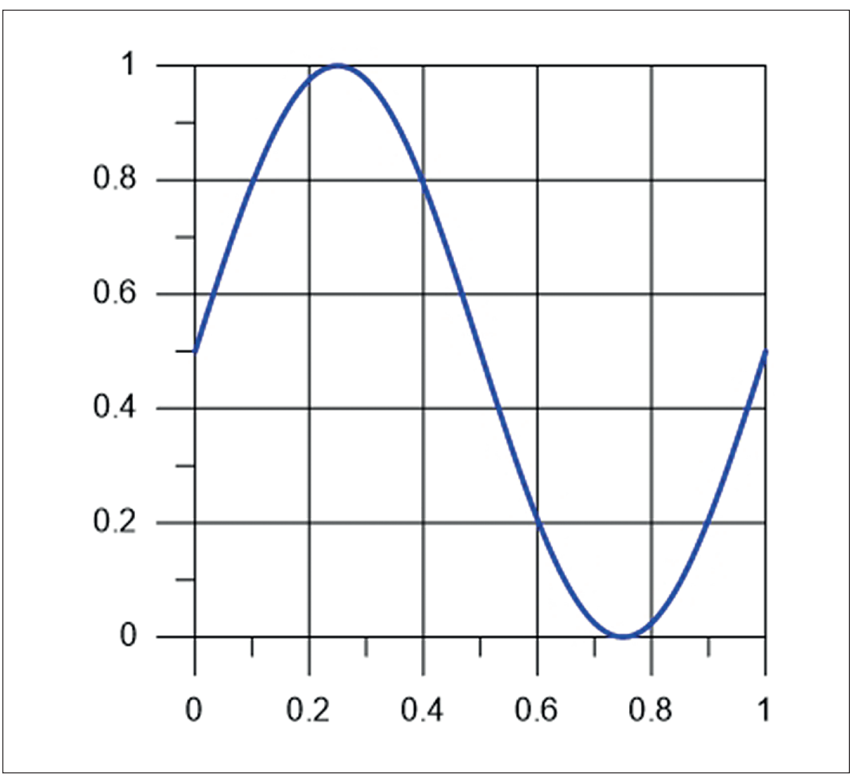

Fig. 7. The assumed fatigue load

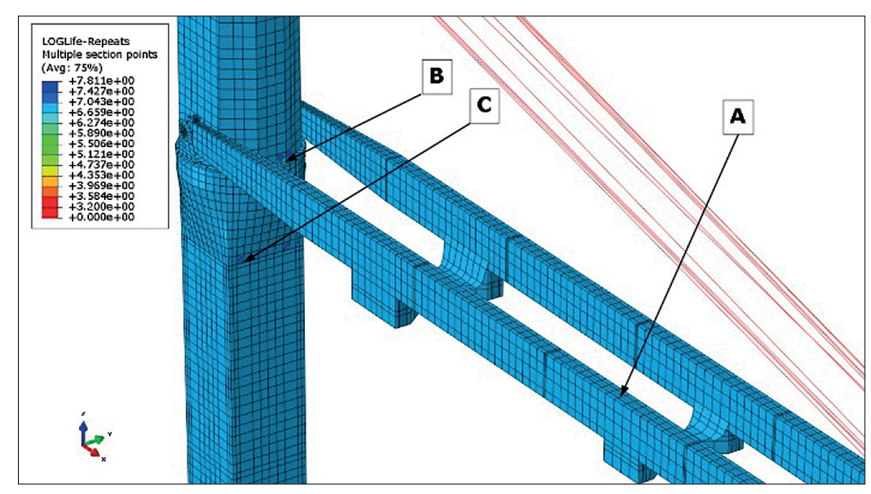

Fig. 8. Permissible number of cycles
The fe-safe system was also used to determine fatigue life (FL); it is the number of cycles (N) after which material fatigue will occur for a given value of stress. The higher the value of $\mathrm{N}$ means the higher the value of fatigue life. Figure 8 presents example contour lines of FL factor, determined for the surface finish factor $K_{f}=1$ and $\sigma_{m} / \sigma_{a}=1$. The higher the value of FL, the higher the value of fatigue life. For the previously selected points, the fatigue results are given in Table 3 for material A and Table 4 for material B, respectively.

Tab. 5. Results of fatigue calculations for selected points of the crane's structural elements for material $B$

\begin{tabular}{|c|c|c|c|}
\hline $\begin{array}{c}\text { Part of the } \\
\text { crane }\end{array}$ & $\begin{array}{c}\text { Number of } \\
\text { finite elements }\end{array}$ & $\begin{array}{c}\text { Number of } \\
\text { cycles }\end{array}$ & Damage/cycle \\
\hline Jib (A zone) & 102,214 & $\begin{array}{c}\text { No fatigue } \\
\text { damage }\end{array}$ & $\begin{array}{c}\text { No fatigue } \\
\text { damage }\end{array}$ \\
\hline $\begin{array}{c}\text { Crane housing } \\
\text { (B zone) }\end{array}$ & 300,714 & 163,538 & $6.115 \mathrm{E}-06$ \\
\hline $\begin{array}{c}\text { Column } \\
\text { (C zone) }\end{array}$ & 203,798 & 591,920 & $1.689 \mathrm{E}-06$ \\
\hline
\end{tabular}

Another widely used indicator of fatigue strength is Factor of Strength (FOS). FOS, defining the fatigue strength of a material as a function of working stress, is generally determined by using the Goodman or Soderberg formulas.

According to the Goodman formula, in the system $\left(\sigma_{m}, \sigma_{a}\right)$, FOS is determined from the equation

$$
1 / \mathrm{FOS}=\sigma_{m} / \sigma_{u}+K_{f}\left(\sigma_{a} / \sigma_{f}\right)
$$

where $\sigma_{a}$ is stress amplitude, $\sigma_{m}$ is mean stress, $\sigma_{u}$ is the ultimate (tensile) strength, $\sigma_{f}$ is the fatigue strength denoting the maximum stress at which an element will work an infinite number of cycles, and $K_{f}$ denotes fatigue notch factor.

If the plasticity limitis $\sigma_{y}$ introduced into equation (3), FOS can also be determined according to the Soderberg formula

$$
1 / \mathrm{FOS}=\sigma_{m} / \sigma_{y}+K_{f}\left(\sigma_{a} / \sigma_{f}\right)
$$

Figure 9 presents contour lines of the FOS, that were determined by arbitrarily adopting the surface finish factor $K_{f}=1$ and $\sigma_{m} / \sigma_{a}=1$.

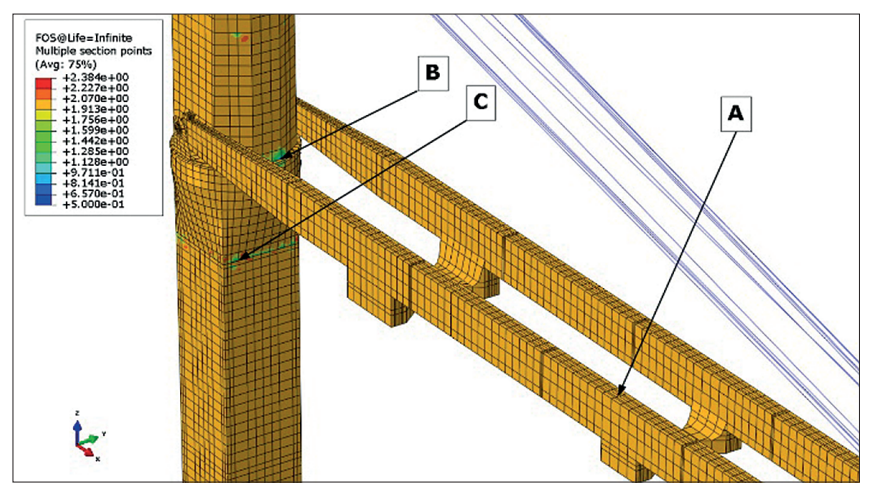

Fig. 9. Distribution of the Factor of Strength (FOS) 
In the area marked B in the housing, the FOS assumes a value of 0.631 . At point $C$ on the column it is 1.218 while, at point $\mathrm{A}$ of the jib, FOS equals 2.0.

For the assumed zero-pulsating fatigue cycle, the influence of the average stress Sm (mean stress) was taken into account when adopting the Goodman formula. The graph of the stresses of Sa ('alternate stress') depending on the number of cycles, is shown in Figure 10.

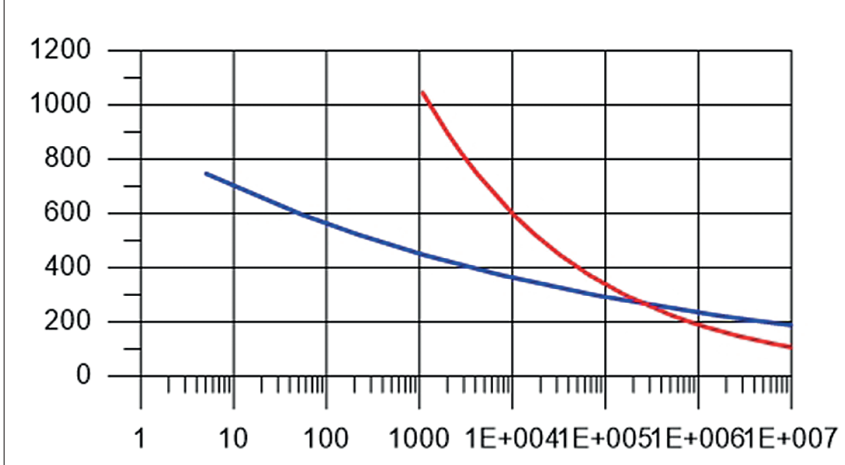

Fig. 10. Diagram of alternating stresses ( $\mathrm{Sa}$ ) versus the number of cycles (N). Material $A$ and $B$

\section{CONCLUSIONS}

We determined the thicknesses of the metal plates used for the plating of the column, crane housing and the jib, and then selected and laid out the longitudinal and transverse stiffeners. Particular attention was paid to the modelling of those areas of the structure that are crucial to the safe crane operation (tie elements, pin joint connecting the jib and housing). When discretising tie elements, one should bear in mind that the mechanical properties of braided steel ropes substantially differ from the properties of individual component wires. The modelling of a structure by finite elements requires a careful choice of these elements. For instance, for a model of a girder, the ABAQUS library offers a number of plate and shell finite element types. Adopting incorrect finite elements may lead to wrong calculation results, regardless of the mesh density. According to the recommendation of the ABAQUS manual [3], thin plates (with a thickness to length ratio less than $1 / 15$ ) were discretised by using shell elements marked as S8R5 (8-node tetragonal elements of a curved shell, reduced numerical integration, five degrees of freedom in a node) or STRI65 (6-node triangular elements, five degrees of freedom in a node). Thick plate elements were modelled with 8-node shell finite elements, denoted as S8R (tetragonal elements, six degrees of freedom in a node, and reduced numerical integration in calculations of the single element stiffness matrix). The fatigue analysis included examination of how the load characteristics (sinusoidal fluctuating, positive zero to tension pulsating and unilateral positive) and fatigue surface finish factor affect fatigue factors FOS and FL in selected regions of the column, the housing and the jib. The greater the values of FOS and FL are, the higher the value of fatigue life is.

Based on the acquired number of cycles of fatigue life it is possible to estimate the practical service life of a structure.
The use of advanced fatigue calculation software, such as fe-safe, allows one to automate and accelerate fatigue calculations of structures for real load cycles, measured experimentally. Such programs include advanced calculation models of fatigue strength as well as the most basic ones, which are included in the regulations and approved by classification institutions. Correctly performed numerical fatigue calculations can be accepted by classification institutions.

\section{PRACTICAL RECOMMENDATIONS}

1. Fatigue calculations (high-cycle fatigue strength) based on S-N curves are the basic calculations for the design of fatigue strength and for determining the life span of ship and offshore structures. These calculations reduce the probability of the formation and development of fatigue cracking (fracture mechanics) at the design stage (due to the probabilistic nature of loads and the dispersion of material property inaccuracies in performance).

2. Fatigue calculations of structural elements, based on the fracture mechanics according to the recommendations of classification institutions, can supplement those based on the S-N fatigue curves. For this purpose, the recommendations (according to DNV) are based on the known Paris equation describing fatigue (life expectancy and crack development) depending on the stress intensity factor $K$ (not used here), which may be expressed as:

$$
K=\sigma g \sqrt{\pi a}
$$

where $\sigma$ is the normal stress in the member normal to the crack, $g$ denotes the factor depending on the geometry of the member and the crack, and $a$ is crack depth.

3. The development of cracking usually occurs in the area of welded joints. Additional recommendations for the modelling and calculation of fatigue strength of welds are provided in the recommendations of classification institutions. According to DNV, they are also based on S-N curves (for welded joints). Numerical calculations with the use of FEM (appropriate mesh) are recommended with appropriate interpolation of the obtained numerical results regarding the nominal stresses in the area of stress concentration (notch).

4. In the case of crane fatigue strength, the calculations are reduced to fatigue calculations based on $\mathrm{S}-\mathrm{N}$ curves and a comparison of the number of fatigue cycles obtained from calculations with those assumed at the design stage. In the case of ship structures, the operational period is assumed to be 20 years although, currently, there is a tendency to extend this period (up to 30 years or more). 


\section{REFERENCES}

1. K.-J. Bathe, Finite element procedures. 2nd ed. New Jersey, Prentice Hall, 1996.

2. J. Carvill, Mechanical engineer's data handbook. 8th ed. Oxford, Butterworth-Heinemann, 2000.

3. Dassault Systemes Simulia Corp.: ABAQUS version 6.14: user's manual. Providence, Dassault Systemes Simulia Corp. 2014.

4. T. Deguchi, M. Mouri, J. Hara, D. Kano, T. Shimoda, F. Inamura, et al., "Fatigue strength improvement for ship structures by Ultrasonic Peening", J Mar Sci Technol, vol. 17(3), pp. 360-369, 2012.

5. M. Fonte, M. Freitas, B. Li, P. Duarte, L. Reis, "Welding assessment of a damaged crane pedestal of a container ship”, Ciência \& Tecnologia dos Materiais, vol. 27(1), pp. 10-14, 2015.

6. H.O. Fuchs, R.I. Stephens, Metal fatigue in engineering. 1st ed. New York, Wiley, 1980.

7. D.S. Han, S.W. Yoo, H.S. Yoon, M.H. Kim, S.H. Kim, J.M. Lee, "Coupling analysis of finite element and finite volume method for the design and construction of FPSO crane", Automat Constr, vol. 20(4), pp. 368-379, 2011.

8. R.B. Heywood, Designing against fatigue of metals. 1st ed. New York, Reinhold, 1962.

9. S.E. Hirdaris, W. Bai, D. Dessi, A. Ergin, X. Gu, O.A. Hermundstad, et al., "Loads for use in the design of ships and offshore structures", vol. 78, pp. 131-174, 2014.

10. S.E. Hirdaris, N.J. White, N. Angoshtari, M. Johnson, Y. Lee, N. Bakkers, "Wave loads and flexible fluid-structure interactions: current developments and future directions", Ships Offshore Structures, vol. 5(4), pp. 307-325, 2010.

11. R.C. Juvinall, Engineering consideration of strees, strain and strength. 1st ed. New York, McGraw-Hill, 1967.

12. M. Kleiber, C. Woźniak, Nonlinear mechanics of structures. 1st ed. Dordrecht, Kluwer, 1991.

13. M.I. Kvittem, T. Moan, "Time domain analysis procedures for fatigue assessment of a semi-submersible wind turbine", Mar Struct, vol. 40, pp. 38-59, 2015.

14. A.A. Marquez, P. Venturino, J.L. Otegui, "Common root causes in recent failures of cranes", Eng Fail Anal, 39, pp. 55-64, 2014.
15. H.P. Lieurade, "Fatigue analysis in offshore structures", in Advances in Fatigue Science and Technology: Proceedings of the NATO Advanced Study Institute on Advances in Fatigue Science and Technology, Branco CM, Rosa LG, Eds. 1988 Apr 4-15; Alvor, Portugal. Dordrecht, KluwerNATO ASI E Series 159, 1989, pp. 585-625.

16. S. Pałkowski, Konstrukcje cięgnowe. 1st ed. Warszawa, WNT, 1994.

17. P.T. Pedersen, "Marine structures: future trends and the role of universities", Engineering, vol. 1(1), pp. 131-138, 2015.

18. Safe Technology Ltd.: Fe-safe version 6.5: user's manual. Sheffield, Safe Technology Ltd. 2014.

19. 19. C.G. Soares, Y. Garbatov, "Fatigue reliability of the ship hull girder”, Mar Struct, vol. 9(3-4), pp. 495-516, 1996.

20. 20. C.G. Soares, T. Moan, "Model uncertainty in the longterm distribution of wave-induced bending moments for fatigue design of ship structures", Mar Struct, vol. 4(4), pp. 295-315, 1991.

21. P. Wirsching, "Fatigue reliability for offshore structures", J Struct Eng. ASCE, vol. 110(10), pp. 2340-2356, 1984.

22. F. Wu, W. Yao, P. Hu, "Fatigue life prediction analysis of crane structure on the basis of strain signal measure and MSC.Fatigue" in Structural health monitoring and integrity management: Proceedings of the 2 nd International Conference of Structural Health Monitoring and Integrity Management (ICSHMIM 2014); 2014 Sep 24-26; Nanjing, China, pp. 309-314, Boca Raton, CRC Press, 2015.

23. [O. Ozguc, "Assessment of Buckling Behaviour on an FPSO Deck Panel”, Polish Maritime Research, vol. (3), pp. 50-58, 2020.

24. J. Łubiński, H. Olszewski, "Hybrid Finite Element Method Development for Offshore Structures. Calculation with the Implementation of Industry Standards", Polish Maritime Research, vol. 26(4), pp. 90100, 2019.

25. L. Samson, M. Kahsin, "A Method to Determine the Tightening Sequence for Standing Rigging of a Mast", Polish Maritime Research, vol. 26(4), pp. 47-55, 2019.

26. E. Zahavi, V. Torbilo, Life expectancy of machine parts: fatigue design, 1st ed. Boca Raton, CRC Press, 1996. 


\section{CONTACT WITH THE AUTHORS}

Ryszard Buczkowski

e-mail:rbuczkowski@ps.pl

West Pomeranian University of Technology Szczecin

Piastów 41, 71-065 Szczecin

Poland

Bartłomiej Żyliński

e-mail:bartek.zylinski@hotmail.com

West Pomeranian University of Technology Szczecin

Piastów 41, 71-065 Szczecin

Poland 